\title{
Acute Stress and Anxiety in Medical Residents on the Emergency Department Duty
}

\author{
Joaquín M. González-Cabrera ${ }^{1}$, María Fernández-Prada ${ }^{2}$, Concepción Iribar ${ }^{3,4}$, \\ Rogelio Molina-Ruano ${ }^{5}$, María Salinero-Bachiller ${ }^{3}$ and José M. Peinado ${ }^{3,4, *}$ \\ 1 Faculty of Education, Universidad Internacional de la Rioja, 26006 Logroño, Spain; \\ joaquín.gonzalez@unir.net \\ 2 Department of Preventive Medicine, Central Hospital of Asturias, 33006 Oviedo, Spain; \\ mariafdezprada@gmail.com \\ 3 Department of Biochemistry, Molecular Biology and Immunology 3, University of Granada, \\ 18016 Granada, Spain; mciribar@ugr.es (C.I.); msaliner@correo.ugr.es (M.S.-B.) \\ 4 Institute of Neuroscience "Federico Olóriz", University of Granada, 18012 Granada, Spain \\ 5 Emergency Department, Virgen de las Nieves University Hospital, 18014 Granada, Spain; \\ rogeliomolina22@gmail.com \\ * Correspondence: jpeinado@ugr.es; Tel.: +34-958-243-523; Fax: +34-958-249-015
}

Received: 15 February 2018; Accepted: 6 March 2018; Published: 13 March 2018

\begin{abstract}
The objectives of this longitudinal study were to compare salivary cortisol release patterns in medical residents and their self-perceived anxiety levels between a regular working day and a day when on call in the emergency department (ED-duty day) and to determine any differences in cortisol release pattern as a function of years of residency or sex. The study included 35 residents (physicians-in-training) of the Granada University Hospital, Granada, Spain. Acute stress was measured on a regular working day and an ED-duty day, evaluating anxiety-state with the Spanish version of the State-Trait Anxiety Inventory. Physiological stress assessment was based on salivary cortisol levels. Cortisol release concentrations were higher on an ED-duty day than on a regular working day, with a significantly increased area under the curve (AUC) $(p<0.006)$. This difference slightly attenuated with longer residency experience. No gender difference in anxiety levels was observed $(p<0.001)$. According to these findings, the hypothalamic-pituitary-adrenal axis activity and anxiety levels of medical residents are higher on an ED-duty day than on a regular working day.
\end{abstract}

Keywords: acute stress; cortisol; medical resident; Emergency Department-duty day; anxiety

\section{Introduction}

It should be kept in mind that stress can be positive (eustress) or negative (distress). Thus, eustress is essential to grow, develop, and achieve high levels of performance in a wide range of tasks and activities. In contrast, distress is considered a potential source of physical and psychological problems, especially when chronic [1,2]. Anxiety and stress are widespread psychological disorders. In a European study, $13.6 \%$ of participants reported an anxiety episode at some point in their life and $6.4 \%$ described this experience during the previous year [3]. Acute and chronic stress has been associated with physiological impairments [4,5], psycho-somatic diseases and, especially, cardiovascular disease [6]. It has been reported that anxiety levels are higher in healthcare professionals than in the general population, attributed to frequent night-time working, with few hours of sleep, and exhausting workloads, among other causes [7]. This situation is especially relevant in the case of younger physicians with limited experience, who work in an environment of uncertainty [8,9]. Activation of the hypothalamic-pituitary-adrenocortical axis (HPA) by stress is associated with salivary cortisol release, which is increasingly used as a hormonal biomarker for stress [10,11]. Cortisol release follows a daily circadian rhythm, being elevated after awakening and 
relatively reduced in the evening [12]. Cortisol release can be quantified by constructing the area under the curve (AUC). The typical increase in cortisol levels at 20-30 min after awakening in the morning is known as the "cortisol awake response" (CAR) [13]. Variations in cortisol release have also been associated with age, sex, genetic, and environmental factors [14], and release can be increased by pain, hypoglycemia, exercise, and surgery, among others [15]. A meta-analysis of 208 studies on acute stressors in laboratory settings [16] reported a maximum cortisol response at 20-40 min after a stressful event, while stress research in real-life settings also revealed significant changes in CAR [17]. In clinical studies, it has been reported that cortisol levels are higher with greater severity of illness [18,19]. In addition, a real-life longitudinal study revealed impaired patterns of cortisol release in medical students when facing examinations for a position as resident [20] or when delivering a presentation in public [21]. During their training period (residency), especially when on emergency department (ED) duty, young physicians are given a progressively increasing workload paralleled by an increasing level of related stress [22,23]. Together with sleep deprivation and long work hours, their elevated stress might compromise the correct management of patients [24], and one study reported that relevant levels of anxiety can be experienced by $20-30 \%$ of medical residents [9]. Our study hypotheses were that higher anxiety-state levels in residents on days that included an on-call shift in the emergency department (ED-duty day) would impact on their normal pattern of cortisol release and that these effects would be attenuated as residents became more experienced. The objectives of the study were to compare the patterns of release of salivary cortisol and perceived anxiety-state levels in medical residents between a regular working day and an ED-duty day, and to compare cortisol release patterns as a function of years of residency.

\section{Methods and Subjects}

\subsection{Population and Study Sample}

A longitudinal study was conducted during February and March 2015. The eligible population comprised 88 medical residents: 41 first-year (R1), 34 second-year (R2), and 13 third-year (R3) residents. After application of inclusion and exclusion criteria, 40 residents were enrolled and signed their approval for participation was obtained from 40 of the eligible residents, but two of these dropped out and three were lost due to the incorrect collection of saliva samples. Therefore, the final study sample comprised 35 residents (19 R1, 11 R2, and 5 R3), 11 males (31\%) and 24 females (69\%), with a mean ( \pm standard deviation, SD) age of 26.39 (1.56) years (range, 25-30 years). Participants reported a mean of 6.90 (0.57) h of sleep and a mean of 68.33 (18.25) h on ED duty/month, ranging from 40 to $140 \mathrm{~h} / \mathrm{month}$. In our setting, the standard shift for residents is from 8:00 to 15:00 h, and this is extended until 08:00 $\mathrm{h}$ on the next day for the ED duty shift, which is compulsory for residents of all specialties. The study inclusion criterion was to have been on duty for at least $40 \mathrm{~h} /$ month in the ED of our hospital. Exclusion criteria were: (a) a reported traumatic psychological event in the previous six months; (b) pregnancy; (c) failure to collect saliva correctly; (d) use of medication that might interfere with cortisol metabolism and release (e.g., oral contraceptives); and (e) performance of vigorous physical exercise $>2 \mathrm{~h} /$ day.

\subsection{Data Collection}

(1) Data were gathered on sex, age, hours of sleep on study days, mean number of hours on ED duty/month, and year of residency (to analyze possible interferences with cortisol release patterns) [25].

(2) Saliva samples were collected in Salivette tubes (Sarstedt International, Nümbrecht, Germany), centrifuged at $2555 \times \mathrm{g}$. for $8 \mathrm{~min}$ and stored at $-22{ }^{\circ} \mathrm{C}$ until further analysis. Salivary cortisol concentrations $(\mu \mathrm{g} / \mathrm{dL})$ were measured using an electrochemiluminescence immunoassay (Elecsys Cortisol test kit, Roche Diagnostics, Barcelona, Spain) on a Cobas c8000 analyzer (Roche Diagnostics). Salivary cortisol is a valid and reliable marker of the level of this hormone in plasma [16] and its collection is non-invasive, with minimal impact on daily life [25]. 
(3) State-Trait Anxiety Inventory (STAI) [26]. This stress assessment instrument measures two dimensions of anxiety: trait anxiety (T) and state anxiety (S). We used the state anxiety subscale (STAI-S), which has adequate validity and reliability and has been validated for Spanish populations [27].

\subsection{Procedure}

Informed written consent was obtained from all participants. Each participant collected saliva samples on a regular working day and then, within a maximum of 20 days, on an ED-duty day. On each collection day, a sample of saliva was collected at six time points: (1) immediately after awakening ( \pm 07:00 h); (2) $30 \mathrm{~min}$ after awakening; (3) 11:00 h; (4) 15:00 h (at end of workday or beginning of duty shift); (5) 20:00 h; and (6) 23:00 h [28]. Psychological stress variables were also assessed (between 08:00 $\mathrm{h}$ and 09:00 $\mathrm{h}$ ) on both a regular working day and an ED-duty day.

\subsection{Ethical Considerations}

Participation in the study was voluntary and anonymous. Participants received no compensation and were informed that they could withdraw at any time without disadvantage. The study was approved by the Biomedical Research Ethics Committee of Granada Hospital, Spain.

\subsection{Data Analysis}

SPSS 20.0 software (IBM, Armonk, NY, USA) was used for statistical analyses, and graphs were plotted with SigmaPlot 11.0 (Systat Software, San Jose, CA, USA). Because the data were non-normally distributed (Shapiro-Wilk test), they were first logarithmically transformed $(\ln (x+1))$ and then analyzed with Levene's test to confirm the variance homogeneity. Descriptive statistical analysis (measures of central tendency/dispersion and frequencies) was followed by application of the bilateral Student's $t$-test for dependent (related) samples, the chi-square $\left(\chi^{2}\right)$ test, and one-factor ANOVA, and construction of the AUC using the trapezoidal method in hours [29]. Cohen's $d$ was determined as a measure of the effect size. CAR values were calculated by subtracting cortisol levels at awakening from cortisol levels 30 min later [28]. $p<0.05$ was considered significant in all tests.

\section{Results}

\subsection{Comparison of Salivary Cortisol between Regular Working Days and ED-Duty Days}

Table 1 compares cortisol concentrations at each time point between regular working days and ED-duty days.

Table 1. Mean cortisol values ( $n=35$ residents) on normal versus emergency department (ED)-duty days at each collection time.

\begin{tabular}{|c|c|c|c|c|c|}
\hline Time points & Regular Work Day & ED-Duty Day & Student's $t$-Test $(t)$ & $p$ Value & Effect Size $(d)$ \\
\hline Upon awakening & $\begin{array}{l}0.467( \pm 0.198)^{\mathrm{a}} \\
0.375( \pm 0.127)^{\mathrm{b}}\end{array}$ & $\begin{array}{l}0.551( \pm 0.221) \\
0.429( \pm 0.136)\end{array}$ & $\begin{array}{c}2.033 \\
(-0.108 ;-0.001)\end{array}$ & $0.050 *$ & 0.41 \\
\hline After $30 \mathrm{~min}$ & $\begin{array}{l}0.736( \pm 0.310)^{\mathrm{a}} \\
0.538( \pm 0.167)^{\mathrm{b}}\end{array}$ & $\begin{array}{l}0.819( \pm 0.279) \\
0.587( \pm 0.154)\end{array}$ & $\begin{array}{c}-1.635 \\
(-0.109 ; 0.012)\end{array}$ & 0.112 & 0.30 \\
\hline At $11: 00 \mathrm{~h}$ & $\begin{array}{l}0.247( \pm 0.116)^{\mathrm{a}} \\
0.217( \pm 0.087)^{\mathrm{b}}\end{array}$ & $\begin{array}{l}0.358( \pm 0.192) \\
0.298( \pm 0.126) \\
\end{array}$ & $\begin{array}{c}-5.686 ; \\
(-0.109 ;-0.051)\end{array}$ & 0.001 * & 0.75 \\
\hline At $15: 00 \mathrm{~h}$ & $\begin{array}{l}0.219( \pm 0.119)^{\mathrm{a}} \\
0.193( \pm 0.092)^{\mathrm{b}}\end{array}$ & $\begin{array}{l}0.494( \pm 0.210) \\
0.392( \pm 0.139)\end{array}$ & $\begin{array}{c}-8.283 ; \\
(-0.248 ;-0.151) \\
\end{array}$ & $0.001 *$ & 1.68 \\
\hline At 20:00 h & $\begin{array}{l}0.151( \pm 0.109)^{\mathrm{a}} \\
0.137( \pm 0.086)^{\mathrm{b}}\end{array}$ & $\begin{array}{l}0.207( \pm 0.157) \\
0.181( \pm 0.110)\end{array}$ & $\begin{array}{c}-1.966 \\
(-0.090 ; 0.001)\end{array}$ & 0.058 & 0.44 \\
\hline At $23: 00 \mathrm{~h}$ & $\begin{array}{l}0.127( \pm 0.074)^{\mathrm{a}} \\
0.117( \pm 0.064)^{\mathrm{b}}\end{array}$ & $\begin{array}{l}0.161( \pm 0.102) \\
0.146( \pm 0.081)\end{array}$ & $\begin{array}{c}-2.040 \\
(-0.057 ;-0.001)\end{array}$ & $0.050 *$ & 0.40 \\
\hline
\end{tabular}

a real values expressed in $\mu \mathrm{g} / \mathrm{dL}^{\mathrm{b}}{ }^{\mathrm{b}}$ logarithmic transformations $\ln (\mathrm{x}+1){ }^{*}{ }^{\text {statistically significant difference. }}$ 
Figure 1 displays the standard circadian release pattern of participants on all studied days, with an increase upon awakening and then a progressive decrease, reaching the lowest values before going to bed. Salivary cortisol levels were significantly higher on ED-duty days than on regular working days at 7:00 h. $(p<0.05), 11: 00$ h. $(p<0.001), 15: 00$ h. $(p<0.001)$, and 23:00 h. $(p<0.05)$. The significantly higher cortisol release peak at 15:00 $\mathrm{h}$ on ED-duty days coincides with the start of the duty shift.

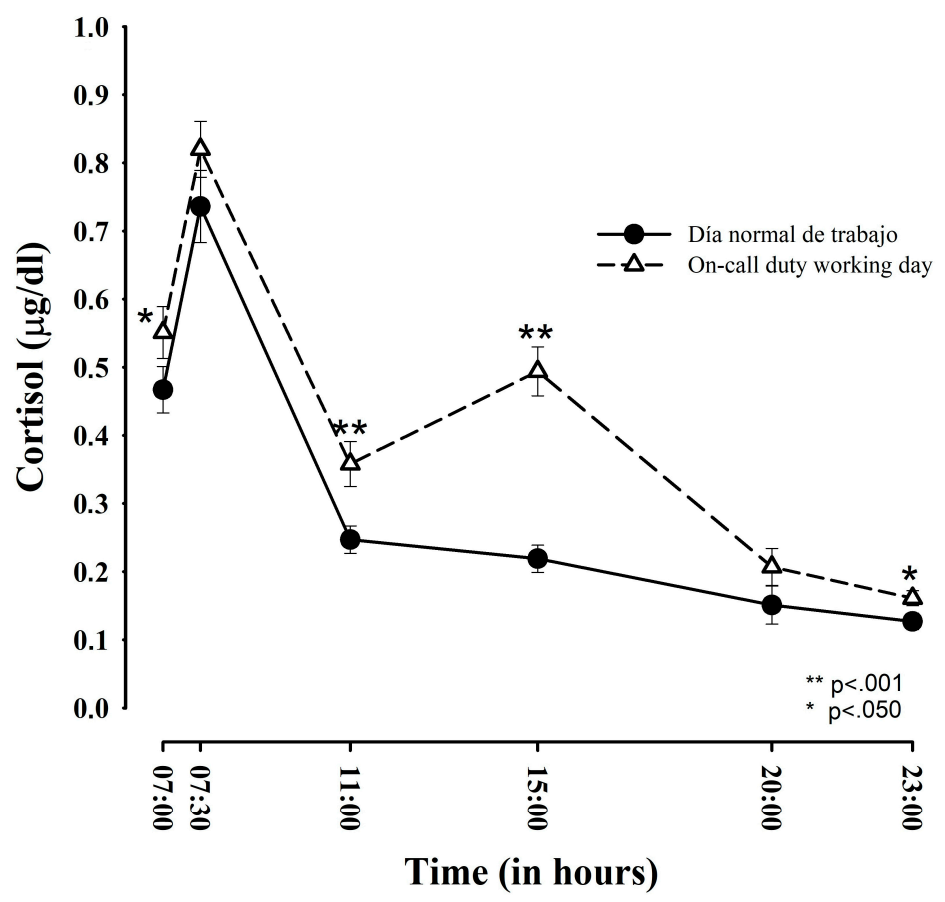

Figure 1. Comparison of salivary cortisol release profiles between regular working day and emergency department (ED)-duty day $(n=35)$.

Table 2 exhibits the AUC and CAR results obtained. ED-duty days and regular working days only significantly differed in AUC values $(p<0.001)$.

Table 2. Mean area under the curve (AUC) and cortisol awake response (CAR) values for the 35 residents on regular working day versus ED-duty day.

\begin{tabular}{|c|c|c|c|c|}
\hline & Total AUC & $\begin{array}{l}\text { Bilateral Student's } t \\
\text { and Cohen's } d\end{array}$ & CAR & $\begin{array}{c}\text { Bilateral Student's } t \\
\text { and Cohen's } d\end{array}$ \\
\hline Regular working day & $8.777( \pm 3.811)^{\mathrm{a}}$ & $t=-7.959$ & $0.2689( \pm 0.238)$ & $t=-0.064$ \\
\hline Day on duty & $\begin{array}{c}2.214( \pm 0.362)^{\mathrm{b}} \\
13.620( \pm 5.199)^{\mathrm{a}} \\
2.623( \pm 0.352)^{\mathrm{b}}\end{array}$ & $\begin{array}{c}p<0.001 * \\
(-0.513 ;-0.304) \\
d=115\end{array}$ & $\begin{array}{l}0.2213( \pm 0.285) \\
0.2682( \pm 0.214) \\
0.2242( \pm 0.165)\end{array}$ & $\begin{array}{c}p<0.950 \\
(0.044 ;-0.093) \\
d=0.01\end{array}$ \\
\hline
\end{tabular}

${ }^{a}$ real values in $\mu \mathrm{g} / \mathrm{dL} ;{ }^{b}$ logarithmic transformations $\ln (\mathrm{x}+1) ;{ }^{*}$ statistically significant difference; AUC: area under the curve; $\mathrm{CAR}=$ cortisol awake response

\subsection{Socio-Demographic Variables and Salivary Cortisol Release}

No significant gender differences were found in cortisol release, AUC, or CAR values on either regular working days or ED-duty days $\left(\chi^{2}=32.550, p<0.296\right)$. Likewise, no significant differences were observed in cortisol release levels by year of residency $\left(\mathrm{F}_{2,32}=1.683, p<0.202\right)$ (see Figure 2 ), age $\left(\mathrm{F}_{5,29}=0.337, p<0.886\right)$, hours of sleep $\left(\mathrm{F}_{2,32}=2.626, p<0.088\right)$, or number of hours on duty $\left(\mathrm{F}_{10,24}=2.414, p<0.057\right)$ on either ED-duty days or regular working days. 


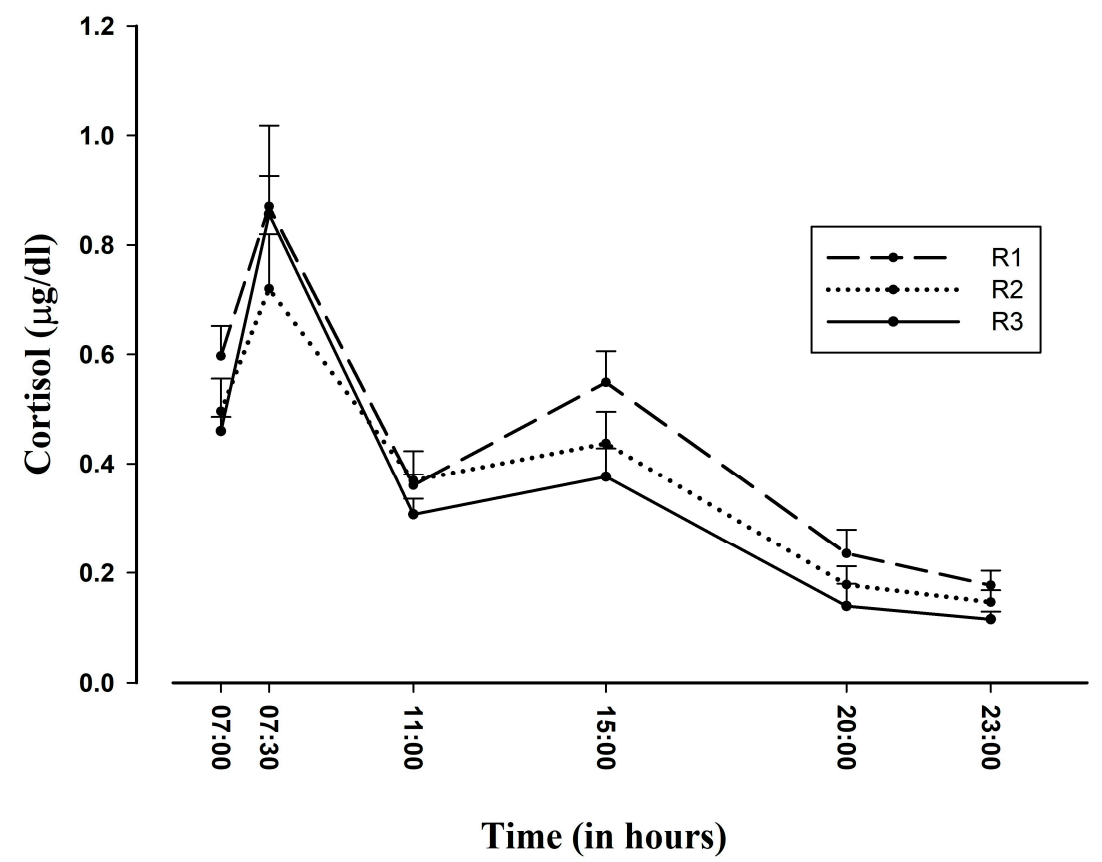

Figure 2. Cortisol profile on ED-duty days as a function of year of residency (arithmetic mean $( \pm \mathrm{SEM})$ in 35 residents). SEM: standard error of the mean; R1: first year of residency; R2: second year of residency; R3: third year of residency.

\subsection{Psychological Scores in Anxiety-State}

STAI-S results were compared with reference population values published by Spielberger et al. [26] and Guillén-Riquelme and Buela-Casal [27]. In comparison with the former, a significant increase in state anxiety was only observed in female residents on ED-duty days. In comparison with the latter reference values (Guillén-Riquelme and Buela-Casal), a significant increase in anxiety was recorded in both male and female residents on ED-duty days (see Table 3).

Table 3. State-Trait Anxiety Inventory (STAI)-State anxiety scores on regular working day versus ED-duty day and comparison with population reference values of Spielberger et al. [26] and Guillén-Riquelme and Buela-Casal [27].

\begin{tabular}{ccccc}
\hline & \multicolumn{2}{c}{ Regular Working Day } & \multicolumn{2}{c}{ ED-Duty Day } \\
\cline { 2 - 5 } & Males & Females & Males & Females \\
\cline { 2 - 5 } & $\boldsymbol{n}=\mathbf{1 1}$ & $\boldsymbol{n}=\mathbf{2 4}$ & $\boldsymbol{n}=\mathbf{1 1}$ & $\boldsymbol{n}=\mathbf{2 4}$ \\
\hline \multirow{2}{*}{ STAI-State (comparison with data from } & $19.08( \pm 5.07)$ & $20.17( \pm 5.24)$ & $23.42( \pm 5.93)$ & $25.70( \pm 5.82)$ \\
Spielberger et al. [26]) & $p=0.344$ & $p=0.009^{*}$ & $p=0.121$ & $p=0.037^{*}$ \\
& $t=-0.988$ & $t=-2.858$ & $t=1.680$ & $t=2.217$ \\
\hline \multirow{2}{*}{ STAI-State (comparison with data from } & $19.08( \pm 5.07)$ & $20.17( \pm 5.24)$ & $23.42( \pm 5.93)$ & $25.70( \pm 5.82)$ \\
Guillén-Riquelme and Buela-Casal [27]) & $p=0.052$ & $p=0.085$ & $p=0.001^{*}$ & $p=0.001^{*}$ \\
& $t=2.180$ & $t=1.805$ & $t=4.408$ & $t=6.936$ \\
\hline
\end{tabular}

Reference population state anxiety subscale (STAI-S) values are 20.54 for males and 23.30 for females according to Spielberger et al. [26], and 15.87 for males and 18.20 for females according to Guillén-Riquelme and Buela-Casal [27]; * statistically significant difference.

STAI-state results also showed that anxiety levels were significantly higher on ED-duty days than on regular working days in both males $(p<0.001)$ and females $(p<0.001)$. 


\section{Discussion}

According to the results of this study of medical residents in a real-life setting, salivary cortisol levels and anxiety are increased on ED-duty days. Controversial findings have been published on cortisol response to stress in healthcare professionals, with some authors reporting higher cortisol concentrations than described for the general population among emergency physicians [19] and surgeons [30], while others have found no differences among emergency physicians [31] or intensive care unit nurses [32]. In the present study, cortisol levels of medical residents were increased on ED-duty days but not on regular working days. In comparison to a regular working day, the increase in cortisol release was statistically significantly higher upon awakening $(p<0.05)$ and was even more significant at 11:00 h, four hours before starting the ED duty shift $(p<0.01)$, and at 15:00 h, when this shift started $(p<0.01)$. These significant increases suggest a physiological response to anticipatory stress $[20,33]$ that may possibly result from the emotional "footprint" left by previous experience on ED shifts. A similar anticipatory response was observed before official examinations for medical specialty training (Médico Interno Residente, MIR) positions [20,33]. These changes in the cortisol release pattern were verified by the AUC curve results, which showed significantly larger values on ED-duty days, and this appears to be associated with specific time periods of negative mood or self-perceived stress rather than with chronic stress [34]. In fact, both on regular working days and ED-duty days, cortisol release followed the standard pattern, with the highest values at $30 \mathrm{~min}$ after awakening and the lowest at the end of the day.

CAR values did not significantly differ between ED-duty days and regular working days and have been described as more precise than AUC for the evaluation of chronic stress [17,35], although this has not been conclusively established [13]. In the present study, the AUC was significantly larger on ED-duty days than on regular working days; however, between-day differences in CAR values did not reach significance, suggesting that the stress caused by night duties is acute.

Unexpectedly, no relationship was observed between cortisol levels and year of residency. Hence, our hypothesis of an attenuation in cortisol-measured stress with greater experience was rejected, although the peak of cortisol at the start of duty (15:00) tended to flatten with more years of residency. This contrasts with findings in teachers of an improvement in HPA adaptation with longer experience [36]. These data point to a high alteration of HPA that is not significantly reduced by experience, although we observed a progressive reduction between the first and third year of residence. In terms of the eustress-distress continuum, the alteration in the first-year residents may have been more related to distress, due especially to their scant clinical experience, whereas eustress might be more likely to play a role in the HPA alteration observed in the second- and especially third-year residents. However, further research is required to elucidate this issue.

Psychological stress (anxiety) scores paralleled the increase in cortisol release on ED-duty days, when the anxiety scores for both male and female residents were significantly higher than for the reference population published by Guillén-Riquelme and Buela-Casal [27] and those for the females were higher than for the population described by Spielberg [26]. These data are in line with the findings of Buddeberg-Fischer et al. [9].

No significant relationship was observed between cortisol levels and age, hours on duty per month, or hours of sleep, which are potential confounders [25]. Most stress induction studies in laboratory settings have reported higher cortisol levels in males than in females [16,25], whereas real-life investigations have found higher levels in females [31,37] or, as in the present study, no difference between sexes $[11,19,20]$.

Study limitations include the small sample size, although it is similar to some previous investigations $[15,19,20,38-40]$, and the failure to control for other confounders (e.g., menstrual cycle, medical specialty, etc.). The reduction from 88 to 35 participants largely resulted from the application of study eligibility criteria but may have caused some selection bias. A further limitation is associated with the use of non-equivalent control groups to compare among different years of residence. Longitudinal studies with a repeated-measures design are warranted to follow residents from the beginning to 
end of their specialty training and to take into account additional psychological constructs such as depression, which has been associated with cortisol changes.

\section{Conclusions}

This study contributes to the scant literature on patterns of cortisol release in healthcare professionals and provides complementary psychological data $[12,13,28,29]$. These findings indicate an HPA alteration on ED-duty days, especially during the first years of residency, suggesting the need for emotional and stress control interventions to reduce the stress of residents on ED-duty days and its negative impact on their quality of life and health [41] as well as its potentially negative effects on patient safety.

Acknowledgments: The authors are grateful to the residents who participated in the study. They also thank Cruz Miguel Cendán Martínez (University of Granada, Granada, Spain) for his assistance with the application of SigmaPlot.

Author Contributions: Joaquín M. González-Cabrera wrote an initial version of the manuscript, carried out the data analyses and produced the tables and graphics. María Fernández-Prada contributed to the initial design, acquisition, analysis and interpretation of the data, and writing of the manuscript. Concepción Iribar contributed to the design of the experiments, reviewed the literature, and revised the manuscript. Rogelio Molina-Ruano contributed to the data acquisition and supervised the data analysis. María Salinero-Bachiller reviewed the literature, revised the manuscript and contributed to the writing of the final version of the manuscript. José M. Peinado contributed to the conception and design of the research, obtained and allocated the funding, and supervised the data collection and analysis. He wrote and corrected the first versions of the manuscript. All authors approved the final version of the document.

Conflicts of Interest: The authors report no conflicts of interest.

\section{References}

1. Le Fevre, M.; Matheny, J.; Kolt, G.S. Eustress, distress, and interpretation in occupational stress. J. Manag. Psychol. 2003, 18, 726-744. [CrossRef]

2. Leung, M.-Y.; Chan, I.Y.S.; Cooper, C.L. Theories of Stress, in Stress Management in the Construction Industry; John Wiley and Sons, Ltd.: Chichester, UK, 2014. [CrossRef]

3. Alonso, J.; Angermeyer, M.C.; Bernert, S.; Bruffaerts, R.; Brugha, T.S.; Bryson, H.; de Girolamo, G.; Graaf, R.; Demyttenaere, K.; Gasquet, I.; et al. Prevalence of mental disorders in Europe: Results from the European Study of the Epidemiology of Mental Disorders (ESEMeD) Project. Acta Psychiatr. Scand. Suppl. 2004, 109, 21-27. [CrossRef] [PubMed]

4. Sonnentag, S.; Fritz, C. Endocrinological processes associated with job stress: Catecholamine and cortisol responses to acute and chronic stressors. In Research in Organizational Stress and Wellbeing: Employee Health, Coping, and Methodologies; Perrewé, P.L., Ganster, D.C., Eds.; Elsevier: Amsterdam, The Netherlands, 2006; pp. 1-59.

5. Chrousos, G.P. Stress and disorders of the stress system. Nat. Rev. Endocrinol. 2009, 5, 374-381. [CrossRef] [PubMed]

6. Kivimäki, M.; Kawachi, I. Work Stress as a Risk Factor for Cardiovascular Disease. Curr. Cardiol. Rep. 2015, 17, 630. [CrossRef] [PubMed]

7. Pereira-Lima, K.; Loureiro, S.R. Burnout, anxiety, depression, and social skills in medical residents. Psychol. Health Med. 2015, 20, 353-362. [CrossRef] [PubMed]

8. Angerer, P.; Petru, R.; Nowak, D.; Weigl, M. Workingconditions and depression in physicians. Dtsch. Med. Wochenschr. 2008, 133, 26-29. [CrossRef] [PubMed]

9. Buddeberg-Fischer, B.; Stamm, M.; Buddeberg, C.; Klaghofer, R. Anxiety and depression in residents-Results of a Swiss longitudinal study. Z. Psychosom. Med. Psychother. 2009, 55, 37-50. [PubMed]

10. Dahlgren, A.; Kecklund, G.; Theorell, T.; Åkerstedt, T. Day-to-day variation in saliva cortisol—Relation with sleep, stress and self-rated health. Biol. Psychol. 2009, 82, 149-155. [CrossRef] [PubMed]

11. Green, A.; Jones, A.D.; Sun, K.; Neitzel, R.L. The association between noise, cortisol and heart rate in a small-scale gold mining community—A pilot study. Int. J. Environ. Res. Public Health 2015, 12, 9952-9966. [CrossRef] [PubMed] 
12. Bigert, C.; Bluhm, G.; Theorell, T. Saliva cortisol-A new approach in noise research to study stress effects. Int. J. Hyg. Environ. Health 2005, 208, 227-230. [CrossRef] [PubMed]

13. Lovell, B.; Moss, M.; Wetherell, M.A. With a little help from my friends: Psychological, endocrine and health corollaries of social support in parental caregivers of children with autism or ADHD. Res. Dev. Disabil. 2012, 33, 682-687. [CrossRef] [PubMed]

14. Kunz-Ebrecht, S.; Kirschbaum, C.; Marmot, M.; Steptoe, A. Differences in cortisol awakening response on work days and weekends in women and men from the Whitehall II cohort. Psychoneuroendocrinology 2004, 29, 516-528. [CrossRef]

15. Taylor, M.K. Trait anxiety and salivary cortisol during free living and military stress. Aviat. Space Environ. Med. 2008, 79, 129-135. [CrossRef] [PubMed]

16. Dickerson, S.S.; Kemeny, M.A. Acute stressors and cortisol response: A theoretical integration and synthesis of laboratory research. Psychol. Rev. 2004, 96, 84-100. [CrossRef] [PubMed]

17. Walker, S.; O'Connor, D.B.; Schaefer, A.; Talbot, D.; Hendrickx, H. The cortisol awakening response: Associations with trait anxiety and stress reactivity. Pers. Individ. Differ. 2011, 51, 123-127. [CrossRef]

18. Sluiter, J.K.; van der Beek, A.J.; Frings-Dresen, M.H. Medical staff in emergency situations: Severity of patient status predicts stress hormone reactivity and recovery. Occup. Environ. Med. 2003, 60, 373-375. [CrossRef] [PubMed]

19. González-Cabrera, J.; Fernández-Prada, M.; Molina-Ruano, R.; Blázquez, A.; Guillén-Solvas, J.; Peinado, J.M. Psychosocial risk at work, self-perceived stress and cortisol in saliva in a sample of emergency physicians in Granada. Emergencias 2012, 24, 101-106.

20. González-Cabrera, J.; Fernández-Prada, M.; Iribar, C.; Peinado, J.M. Acute and chronic stress increase salivary cortisol: A study in the real-life setting of a national examination undertaken by medical graduates. Stress 2014, 17, 149-152. [CrossRef] [PubMed]

21. Mizoguchi, Y.; Sakami, A.; Imamura, Y.; Tsuruta, T.; Egami, M.; Yamada, S. The effect of oral presentation on salivary 3-methoxy-4-hydroxy-phenylglycol (MHPG) and cortisol concentrations in training doctors: A preliminary study. Endocrine 2012, 42, 752-753. [CrossRef] [PubMed]

22. Dyrbye, L.N.; West, C.P.; Satele, D.; Boone, S.; Tan, L.; Sloan, J.; Shanafelt, T.D. Burnout among U.S. medical students, residents, and early career physicians relative to the general U.S. Popul. Acad. Med. 2014, 89, 443-451. [CrossRef] [PubMed]

23. Busireddy, K.R.; Miller, J.A.; Ellison, K.; Ren, V.; Qayyum, R.; Panda, M. Efficacy of interventions to reduce resident physician burnout: A systematic review. J. Grad. Med. Educ. 2017, 9, 294-301. [CrossRef] [PubMed]

24. Mata, D.A.; Ramos, M.A.; Bansal, N.; Khan, R.; Guille, C.; Angelantonio, E.; Sen, S. Prevalence of depression and depressive symptoms among resident physicians. JAMA 2015, 314, 2373-2383. [CrossRef] [PubMed]

25. Kudielka, B.M.; Hellhammer, D.H.; Wüst, S. Why do we respond so differently? Reviewing determinants of human salivary cortisol responses to challenge. Psychoneuroendocrinology 2009, 34, 2-18. [CrossRef] [PubMed]

26. Spielberger, C.D.; Gorsuch, R.L.; Lushene, R. Manual del Cuestionario de Ansiedad Estado/Rasgo (STAI); TEA Ediciones: Madrid, Spain, 1982.

27. Guillén-Riquelme, A.; Buela-Casal, G. Actualización psicométrica y funcionamiento diferencial de los ítems en el state trait anxiety inventory (STAI). Psicothema 2011, 23, 510-515. [PubMed]

28. Stone, A.A.; Schwartz, J.E.; Smyth, J.; Kirschbaum, C.; Cohen, S.; Hellhammer, D. Individual differences in the diurnal cycle of salivary free cortisol: A replication of flattened cycles for some individuals. Psychoendocrinology 2001, 26, 295-306. [CrossRef]

29. Pruessner, J.C.; Kirschbaum, C.; Meinlschmid, G.; Hellhammer, D.H. Two formulas for the computation of the area under the curve represent measures of total hormone concentration versus time-dependent change. Psychoneuroendocrinology 2003, 28, 916-931. [CrossRef]

30. Alobid, I.; De Pablo, J.; Mullol, J.; Centellas, S.; Parramon, G.; Carrasco, J.; Armario, A.; Bernal-Sprekelsen, M. Increased cardiovascular and anxiety outcomes but not endocrine biomarkers of stress during performance of endoscopic sinus surgery: A pilot study among novice surgeons. J. Arch. Otolaryngol. Head Neck Surg. 2011, 137, 487-492. [CrossRef] [PubMed]

31. Nakajima, Y.; Takahashi, T.; Shetty, V.; Yamaguchi, M. Patters of salivary cortisol levels can manifest work stress in emergency care providers. J. Physiol. Sci. 2012, 62, 191-197. [CrossRef] [PubMed] 
32. Fujimaru, C.; Okamura, H.; Kawasaki, M.; Kakuma, T.; Yoshii, C.; Matsuishi, T. Self-perceived work-related stress and its relation to salivary IgA, cortisol and 3-methoxy-4-hydroxyphenyl glycol levels among neonatal intensive care nurses. Stress Health 2012, 28, 171-174. [CrossRef] [PubMed]

33. Gaab, J.; Rohleder, N.; Nater, U.M.; Ehlert, U. Psychological determinants of the cortisol stress response: The role of anticipatory cognitive appraisal. Psychoneuroendocrinology 2005, 30, 599-610. [CrossRef] [PubMed]

34. Bauer, M.E.; Vedhara, K.; Perks, P.; Wilcock, G.K.; Lightman, S.L.; Shanks, N. Chronic stress in caregivers of dementia patients is associated with reduced lymphocyte sensitivity to glucocorticoids. J. Neuroimmunol. 2000, 103, 84-92. [CrossRef]

35. Fries, E.; Dettenborn, L.; Kirschbaum, C. The cortisol awakening response (CAR): Facts and future directions. Int. J. Psychophysiol. 2009, 72, 67-73. [CrossRef] [PubMed]

36. Ritvanen, T.; Louhevaara, V.; Helin, P.; Väisänen, S.; Hänninen, O. Responses of the autonomic nervous system during periods of perceived high and low work stress in younger and older female teachers. Appl. Ergon. 2006, 37, 311-318. [CrossRef] [PubMed]

37. Weibel, L.; Gabrion, I.; Aussedat, M.; Kreutz, G. Work-related stress in an emergency medical dispatch center. Ann. Emerg. Med. 2003, 41, 500-506. [CrossRef] [PubMed]

38. Schulz, P.; Kirschbaum, C.; Prüssner, J.; Hellhammer, D. Increased free cortisol secretion after awakening in chronically stressed individuals due to work overload. Stress Med. 1998, 14, 91-97. [CrossRef]

39. Yu, Y.Z.; Shi, J.X. Relationship between levels of testosterone and cortisol in saliva and aggressive behaviors of adolescents. Biomed. Environ. Sci. 2009, 22, 44-49. [CrossRef]

40. Al-Daghri, N.M.; Al-Othman, A.; Albanyan, A.; Al-Attas, O.S.; Alokail, M.S.; Sabico, S.; Chrousos, G.P. Perceived stress scores among Saudi students entering universities: A prospective study during the first year of university life. Int. J. Environ. Res. Public Health 2014, 11, 3972-3981. [CrossRef] [PubMed]

41. Hamader, G.; Noehammer, E. Psychology of Well-Being: Theory, Perspectives and Practice; Nova Science Publishers: Hauppauge, NY, USA, 2013.

(C) 2018 by the authors. Licensee MDPI, Basel, Switzerland. This article is an open access article distributed under the terms and conditions of the Creative Commons Attribution (CC BY) license (http:/ / creativecommons.org/licenses/by/4.0/). 